\title{
Thyroid disease is associated with an increased risk of breast cancer: a systematic review and meta-analysis
}

\author{
Shi Chen^, Fei Wu, Rui Hai, Qian You, Linjun Xie, Liang Shu, Xiangyu Zhou \\ Department of Thyroid and Vascular Surgery, The Affiliated Hospital of Southwest Medical University, Luzhou, China \\ Contributions: (I) Conception and design: X Zhou, S Chen; (II) Administrative support: X Zhou, S Chen, F Wu; (III) Provision of study materials \\ or patients: S Chen, F Wu, R Hai, Q You, L Xie; (IV) Collection and assembly of data: S Chen, F Wu, R Hai, Q You, L Xie; (V) Data analysis and \\ interpretation: S Chen, L Shu; (VI) Manuscript writing: All authors; (VII) Final approval of manuscript: All authors. \\ Correspondence to: Xiangyu Zhou, MD, PhD. Professor, Department of Thyroid and Vascular Surgery, The Affiliated Hospital of Southwest Medical \\ University, 25 Taiping Street, Jiangyang District, Luzhou 646000, China. Email: Xiangyuzhou971@vip.126.com.
}

\begin{abstract}
Background: This study investigated the relationship between thyroid diseases and the risk of breast cancer (BC). Clarifying this issue can help medical staff perform of early prevention, diagnosis and treatment for breast cancer patients.
\end{abstract}

Methods: The meta-analysis combined data from cohort studies and case-control to obtain a comprehensive result of the relationship between thyroid diseases and risk of BC. We comprehensively searched PubMed, EMbase, Web of Science, and the Cochrane Library. The search period was from the establishment of the databases to August 2020. Literature was collected and screened individually by two reviewers. There was English language restriction on the search and unpublished literature was excluded. The Newcastle-Ottawa Scale (NOS) was used to evaluate the quality of the selected studies prior to data extraction. The data collected included country, author, year of publication, research type, and number of cases. In cases where the data and study heterogeneity permitted, meta-analyses were performed, and odd ratios (ORs) with corresponding 95\% confidence intervals (CIs) were calculated. Data were analyzed using the STATA 15.1 software.

Results: A total of 21 articles were included in this study. Hyperthyroidism, thyroid cancer, thyroglobulin antibody (TGAb) levels, and thyroid microsomal antibody (TPOAb) levels were all significantly associated with an increased risk of BC, while hypothyroidism was associated with a reduced risk of BC.

Conclusions: This study demonstrated that hyperthyroidism, autoimmune thyroiditis (AITD), and thyroid cancer are significantly associated with an increased risk of BC, while hypothyroidism is associated with a reduced risk of $\mathrm{BC}$.

Keywords: Breast cancer (BC); thyroid disease; risk factor; meta-analysis

Submitted Sep 24, 2020. Accepted for publication Jan 11, 2021.

doi: $10.21037 /$ gs-20-878

View this article at: http://dx.doi.org/10.21037/gs-20-878

\section{Introduction}

Breast cancer (BC) is the most common type of cancer in females, occurring in $20 \%$ of the female population worldwide, and is the main cause of tumor-related death in women (1). Studies have shown that BC is closely related to the endocrine system (2). The thyroid is an important part of the endocrine system and secretes thyroid hormone $(\mathrm{TH})$, which plays a vital role in the growth, development, and

^ ORCID: Shi Chen, 0000-0002-9103-3785; Xiangyu Zhou, 0000-0001-8976-9489. 
metabolism of cells and tissues $(3,4)$. As pituitary hormones target both breast and thyroid tissues (5), there may be a correlation between BC and thyroid disorders. Hardefeldt et al. (6) found that there was significant evidence of an increased risk of $\mathrm{BC}$ in patients with presence of antithyroid antibodies, while they also found that there was no significant evidence of an increased risk of $\mathrm{BC}$ in patients with hypothyroidism and hyperthyroidism. But more highquality prospective studies are needed to prove causality the relationship between benign thyroid disease and BC. However, the relationship between $\mathrm{BC}$ and thyroid diseases, such as hyperthyroidism, hypothyroidism, autoimmune thyroid disease (AITD) and thyroid cancer, is still not well understood.

Angelousi and colleagues demonstrated that TH promoted the proliferation of breast cancer cells in vitro, while hypothyroid function resulted in a lower incidence of lymph node metastases (7). Recent studies have suggested that $\mathrm{TH}$ may play a positive role in the cause and development of BC at a cellular level (8-11). However, Hercbergs et al. found no evidence that TH causes BC in the clinical setting (12). Despite numerous studies having investigated the association between thyroid dysfunction and $\mathrm{BC}$, the exact relationship and molecular mechanisms involved remain unclear. Further studies examining the prognostic role of TH in BC are thus warranted.

AITD is a disease whereby the body's own immune cells attack and damage the thyroid tissue. It is characterized by the presence of autoantigens such as thyroglobulin $(\mathrm{Tg})$ and thyroid peroxidase (TPO). In patients with AITD, autoantibodies to the thyroid antigens can be detected in the blood. These autoantibodies include thyroglobulin antibody (TGAb), thyroid microsomal antibody (TPOAb), and thyroid-stimulating receptor antibody (TRAb). Furthermore, the immune system plays a complex role in $\mathrm{BC}$ and autoimmune factors are also crucial in the development of BC, so TGAb and TPOAb may have some correlation with BC. Several studies have shown an increased prevalence of AITD in patients with BC (13-15), while others have found no association (16). In fact, Tosovic and colleagues demonstrated that women with high levels of TPOAb had a relatively lower risk of BC (17).

According to epidemiological statistics, the cumulative incidence of developing a second malignancy in a patient with thyroid cancer is $16 \%$ at 25 years (18). Previous studies have shown that there is a unidirectional or bidirectional association between thyroid cancer, breast cancer and renal cell carcinoma $(19,20)$. A unidirectional association is defined as a primary cancer that increases the relative risk of subsequent cancers, while a bidirectional association indicates that there is a two-way relationship or mutual relationship between two cancers, and has nothing to do with the subsequent occurrence. Thyroid cancer survivors have a high incidence of breast cancer, and breast cancer survivors have a high incidence of thyroid cancer $(21,22)$.

This is the largest-scale meta-analysis, including 21 studies involving 67,049 female breast cancer patients to explore the correlation between thyroid diseases (benign and malignant) and the risk of breast cancer. Base on the data from cohort studies and case-control studies, this metaanalysis examined the relationship between thyroid diseases and the risk of $\mathrm{BC}$, aiming of obtaining a comprehensive and comprehensive result. Understanding this relationship can aid in the early prevention, detection and treatment of patients with BC.

We present the following article in accordance with the PRISMA reporting checklist (available at http://dx.doi. org/10.21037/gs-20-878).

\section{Methods}

\section{Search strategy}

The databases PubMed, EMbase, Web of Science, and the Cochrane Library were searched systematically. The search period was from the establishment of the databases to August 2020. All searches were performed using the combination of medical subject heading terms (MeSH), text words, and keywords. The search terms "breast neoplasms", "breast cancer", "breast cancer tumor", "breast carcinoma", "thyroid disease", "thyroid cancer", "hyperthyroidism", "hypothyroidism", "autoimmune thyroiditis", "TGAb", and "TPOAb". There was English language restriction on the search, and unpublished literature was not included. Based on the references listed in the literature obtained in the initial search, a secondary search was performed and literature retrieval was expanded by manual retrieval.

\section{Literature inclusion and exclusion criteria}

Studies where the patients had a definite diagnosis of BC, hyperthyroidism, hypothyroidism, AITD, or thyroid cancer were included in this meta-analysis. Studies that reported a $95 \%$ confidence interval (CI) and odd ratio 
(OR), or where the $95 \% \mathrm{CI}$ and OR could be calculated from the data presented, were included. Non-English publications, duplicate publications, reviews, editorials, single case reports, studies without full text, and studies with incomplete information, or where the data could not be extracted, were all excluded. Studies of drug-induced thyroid disease, and literature including patients with irrelevant acute or chronic diseases were excluded. Any study that did not meet the inclusion criteria was also excluded.

\section{Literature screening and data extraction}

The literature search, screening, and information extraction were performed independently by two professionally trained researchers. Any discrepancies were resolved by discussion, and the final decisions were made by the corresponding author. The data was collated according to a standardized form, and included the country, author, year of publication, research type, number of cases, and clinical outcomes.

\section{Literature quality assessment}

Two researchers independently adopted the NewcastleOttawa Scale (NOS) to evaluate the quality of the literature (23). Any differences in opinions were resolved through discussion or consultation with a third party. NOS evaluates the quality of a study by assessing four items in the "Research Subject Selection" domain (4 points), one item in the "Comparability between Groups" domain (2 points), and three items in the "Result Measurement" domain (3 points). Each study can have a maximum of 9 possible points. Studies with 7 points or more are regarded as highquality literature, and studies scoring less than 7 points are considered lower-quality literature.

\section{Statistical methods}

Odds ratio (OR) with $95 \%$ CI was used to evaluate whether each thyroid disease was an independent risk factor. The fixed effects model was used for analysis if the heterogeneity tests showed that $\mathrm{P} \geq 0.1$ and $\mathrm{I} \leq 50 \%$. The random effects model was used for combined analysis if the heterogeneity tests showed $\mathrm{P}<0.1$ and $\mathrm{I}^{2}>50 \%$. Sensitivity analyses and meta-regression analyses were used to examine the sources of heterogeneity when required. Symmetry on the funnel plot was used to determine publication bias. All data were analyzed using Stata software (version 15.1).

\section{Results}

\section{Literature search results}

A total of 1,642 articles were obtained by searching through PubMed, EMbase, Web of Science, and the Cochrane library. After excluding duplicate articles, there were 1,420 articles remaining. The abstracts of these publications were reviewed and 1,224 articles were selected. Reading the full text of the articles resulted in the selection of 21 publications suitable for this meta-analysis (Figure 1).

\section{Baseline characteristics and quality assessment of the included studies}

The baseline characteristics and quality assessment of the included studies are shown in Table 1.

\section{Meta-analysis results}

The meta-analysis results demonstrated that patients with hyperthyroidism had a significantly increased risk of BC. The six studies $(3,24-28)$ showed low heterogeneity (OR $=1.12,95 \%$ CI: $1.08-1.16, \mathrm{P}=0.000 ; \mathrm{I}^{2}=34.9 \%$; Figure 2). Contrary to hyperthyroidism, hypothyroidism was significantly correlated with a reduced risk of $\mathrm{BC}$, with no heterogeneity $(\mathrm{OR}=0.95,95 \% \mathrm{CI}: 0.91-1.00, \mathrm{P}=0.042$; $\mathrm{I}^{2}=0.0 \%$; Figure 3$)$ observed in the eight studies (17, 24-27,29-31). Moreover, analysis of five studies (32-36) demonstrated that patients with thyroid cancer had a 1.3fold increased risk of $\mathrm{BC}$, with no heterogeneity observed $\left(\mathrm{OR}=1.28,95 \% \mathrm{CI}: 1.15-1.42, \mathrm{P}=0.000 ; \mathrm{I}^{2}=0.0 \%\right.$; Figure 4$)$.

To examine the effect of AITD on the risk of $\mathrm{BC}$, the relationship between TGAbs or TPOAbs and risk of BC was investigated. Analysis of four studies $(14,15,37,38)$ demonstrated that patients with elevated TGAb levels were 2.6 times more likely to develop $\mathrm{BC}$, and low heterogeneity was observed $(\mathrm{OR}=2.57,95 \% \mathrm{CI}: 1.58-4.18, \mathrm{P}=0.000$; $\mathrm{I}^{2}=0.9 \%$; Figure 5$)$. The analysis of five studies $(14,15,38-40)$ showed that elevated TPOAb levels were also significantly correlated with an increased risk of $\mathrm{BC}(\mathrm{OR}=2.83,95 \% \mathrm{CI}$ : 2.03-3.94, $\mathrm{P}=0.000 ; \mathrm{I}^{2}=0.0 \%$; Figure 5)

\section{Sensitivity analysis}

Sensitivity analyses were performed to evaluate whether 


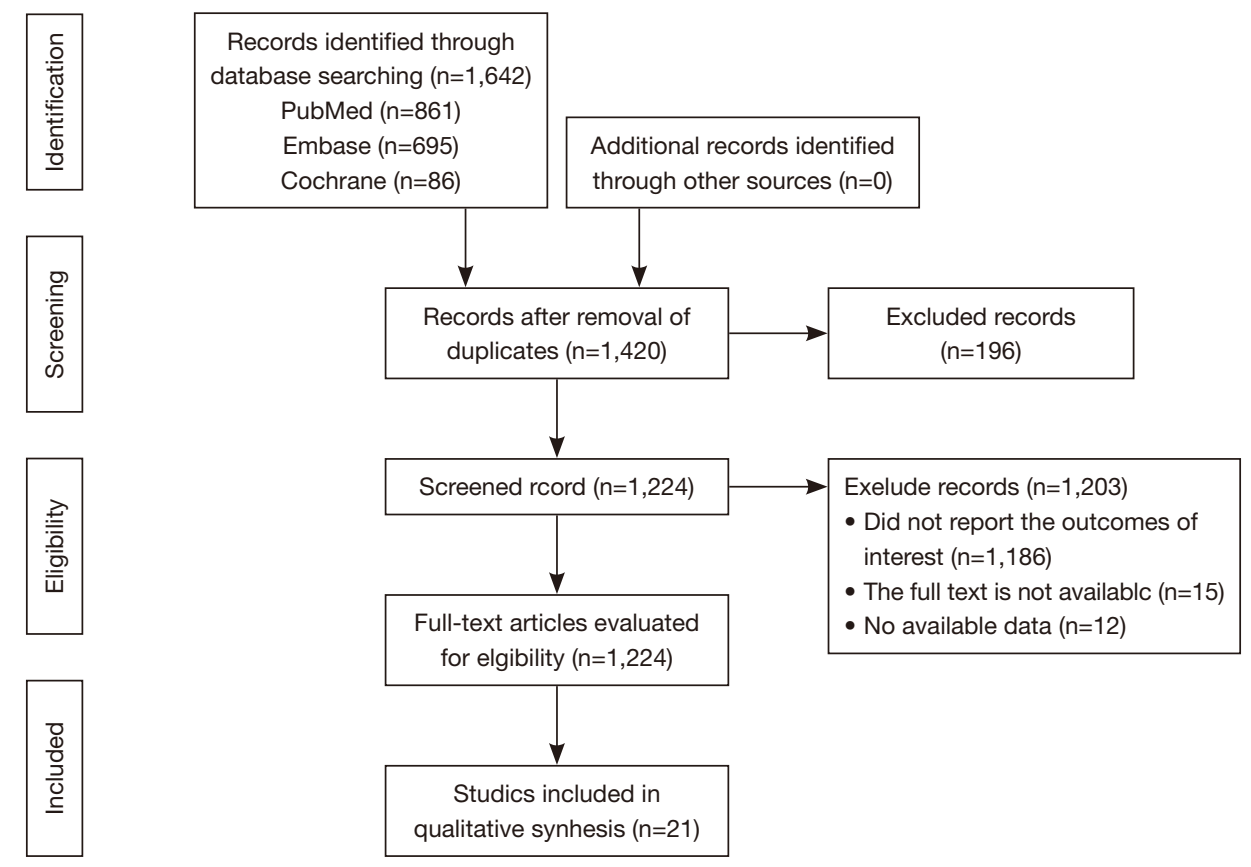

Figure 1 Preferred Reporting Items for Systematic Reviews and Meta-Analyses (PRISMA) flow diagram.

individual studies had an excessive impact on the results of the entire meta-analysis. During sensitivity analyses, the included studies was eliminated one by one, and then the OR value of the remaining studies was calculated. The results demonstrated that none of the studies had an excessive impact on the results of the meta-analysis (Figures S1-S5), indicating that the results of this meta-analysis were stable and reliable.

\section{Publication bias}

Funnel plot analysis was used to assess publication bias. As shown in the Figure 6, the funnel plot was asymmetric, indicating potential publication bias in the results of this meta-analysis.

\section{Discussion}

To our knowledge, this is the largest meta-analysis examining the correlation between thyroid diseases (both benign and malignant) and the risk of $\mathrm{BC}$. A total of 21 studies, involving 67,049 female patients with BC, were analyzed. Our meta-analysis results demonstrated that hyperthyroidism, hypothyroidism, thyroid cancer, and AITD were significantly associated with an increased risk of BC.

The causes of BC are complex. Its occurrence has been closely associated with various factors such as genetic, environmental, social, and behavioral factors, as well as the use of hormones and drugs $(41,42)$. The endocrine system plays a crucial role in the physiology and pathology of the breast. The thyroid, being the largest endocrine organ in the human body, plays a major role in the growth and development of cells through regulating the levels of various hormones in the body. Therefore, understanding the relationship between thyroid diseases and the risk of $\mathrm{BC}$ is of vital importance.

In 2009, a study by Sandhu et al. (31) found no significant association between hypothyroidism and the risk of BC. This contrasted with a prospective cohort study by Søgaard et al. The latter study, involving 61,873 women with hypothyroidism and 80,343 women with hyperthyroidism (27), demonstrated that patients with hypothyroidism had a slightly reduced risk of $\mathrm{BC}$, while patients with hyperthyroidism had an increased risk of BC. In agreement with Søgaard and colleagues, this 
Table 1 Baseline characteristics and quality assessment

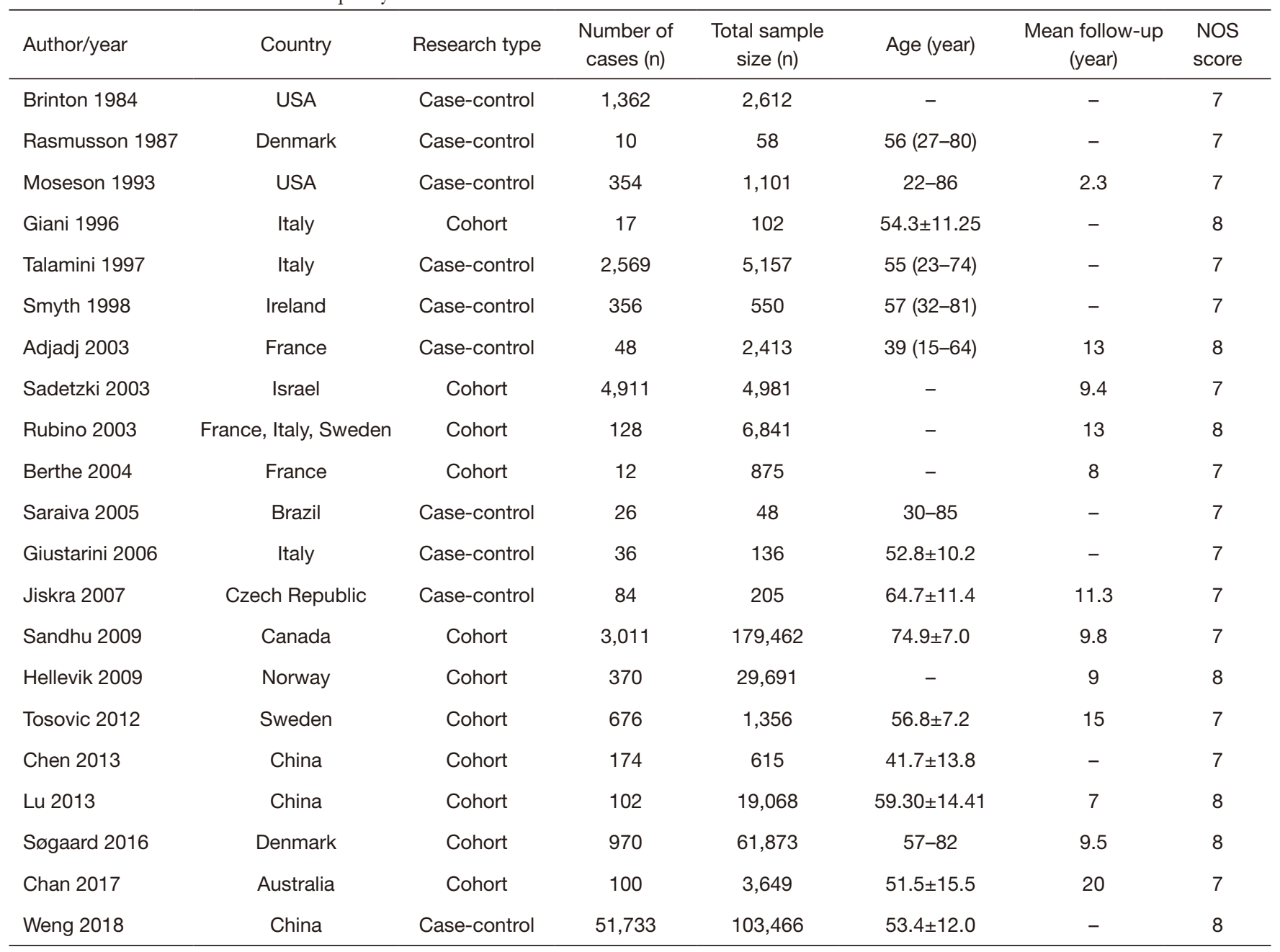

current meta-analysis demonstrated that patients with hypothyroidism had a reduced risk of BC. It is evident that the relationship between thyroid function and the risk of $\mathrm{BC}$ requires further investigation.

Previous in vivo experiments in hypothyroid mice demonstrated that low levels of $\beta$-catenin expression and activation of the apoptosis pathway on the tumor cell membrane inhibited the growth of BC cells in the mice (43). Additionally, in vitro studies using BC cell lines, showed that triiodothyronine (T3), a TH secreted by the thyroid gland, promoted the proliferation of tumor cells and enhanced the cell proliferation effects of estradiol (E2) (44). Hence, it is possible that $\mathrm{TH}$ promotes the occurrence of $\mathrm{BC}$, and patients with hypothyroidism may have a reduced risk of
BC due to lower TH levels. Conversely, hyperthyroidism may lead to an increased risk of $\mathrm{BC}$, as shown in this metaanalysis (OR $=1.12,95 \%$ CI: $1.08-1.16, \mathrm{P}=0.00, \mathrm{I}^{2}=34.9 \%$; Figure 2). The low heterogeneity may be due to differences in thyroid hormone measurement instruments in different literatures, differences in the inclusion and exclusion criteria of experimental subjects. However, Hercbergs et al. (12) found no evidence that $\mathrm{TH}$ causes $\mathrm{BC}$ in the clinical setting (12), despite numerous studies having investigated the association between thyroid dysfunction and BC. That may due to limited clinical and preclinical studies to assess.

An awareness of the relationship between hyperthyroidism and $\mathrm{BC}$ is important in improving the clinical detection 


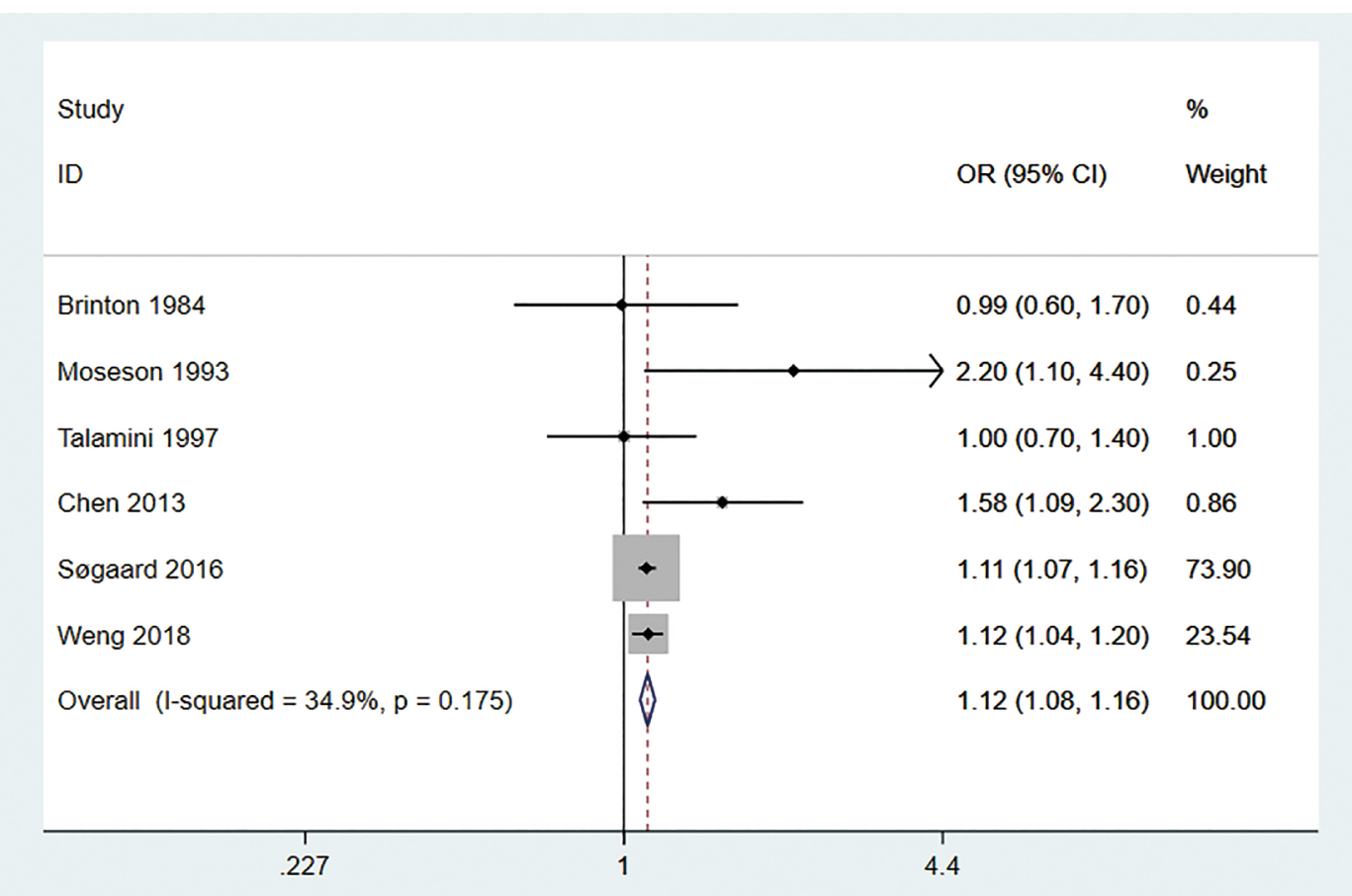

Figure 2 The association between hyperthyroidism and the risk of breast cancer. Patients with hyperthyroidism have a significantly increased risk of breast cancer with low heterogeneity being observed [OR =1.12, 95\% CI: 1.08-1.16, $\mathrm{P}=0.000$; $\mathrm{I}^{2}=34.9 \%$; enrolling 6 studies $(3,24-28)$ ].

\begin{tabular}{|c|c|c|}
\hline \multirow{2}{*}{$\begin{array}{l}\text { Study } \\
\text { ID }\end{array}$} & \multirow[b]{2}{*}{ OR $(95 \% \mathrm{Cl})$} & \multirow{2}{*}{$\begin{array}{l}\% \\
\text { Weight }\end{array}$} \\
\hline & & \\
\hline Brinton 1984 & $1.00(0.80,1.20)$ & 5.18 \\
\hline Moseson 1993 & $0.90(0.50,1.50)$ & 0.71 \\
\hline Talamini 1997 & $0.60(0.30,1.20)$ & 0.44 \\
\hline Sandhu 2008 & $0.99(0.92,1.07)$ & 37.30 \\
\hline Hellevik 2009 & $0.85(0.57,1.25)$ & 1.38 \\
\hline Tosovic 2012 & $0.81(0.62,1.07)$ & 2.86 \\
\hline Søgaard 2016 & $0.94(0.88,1.00)$ & 52.08 \\
\hline Chan 2017 & $0.35(0.05,2.53)$ & 0.06 \\
\hline Overall $(\mathrm{I}$-squared $=0.0 \%, \mathrm{p}=0.561)$ & $0.95(0.91,1.00)$ & 100.00 \\
\hline .05 & 0 & \\
\hline
\end{tabular}

Figure 3 The association between hypothyroidism and the risk of breast cancer. Patients with hypothyroidism have a significantly reduced risk of breast cancer with no heterogeneity being observed $\left[\mathrm{OR}=0.95,95 \% \mathrm{CI}\right.$ : 0.91-1.00, $\mathrm{P}=0.042 ; \mathrm{I}^{2}=0.0 \%$; enrolling 8 studies $(17,24-27,29-31)$. 


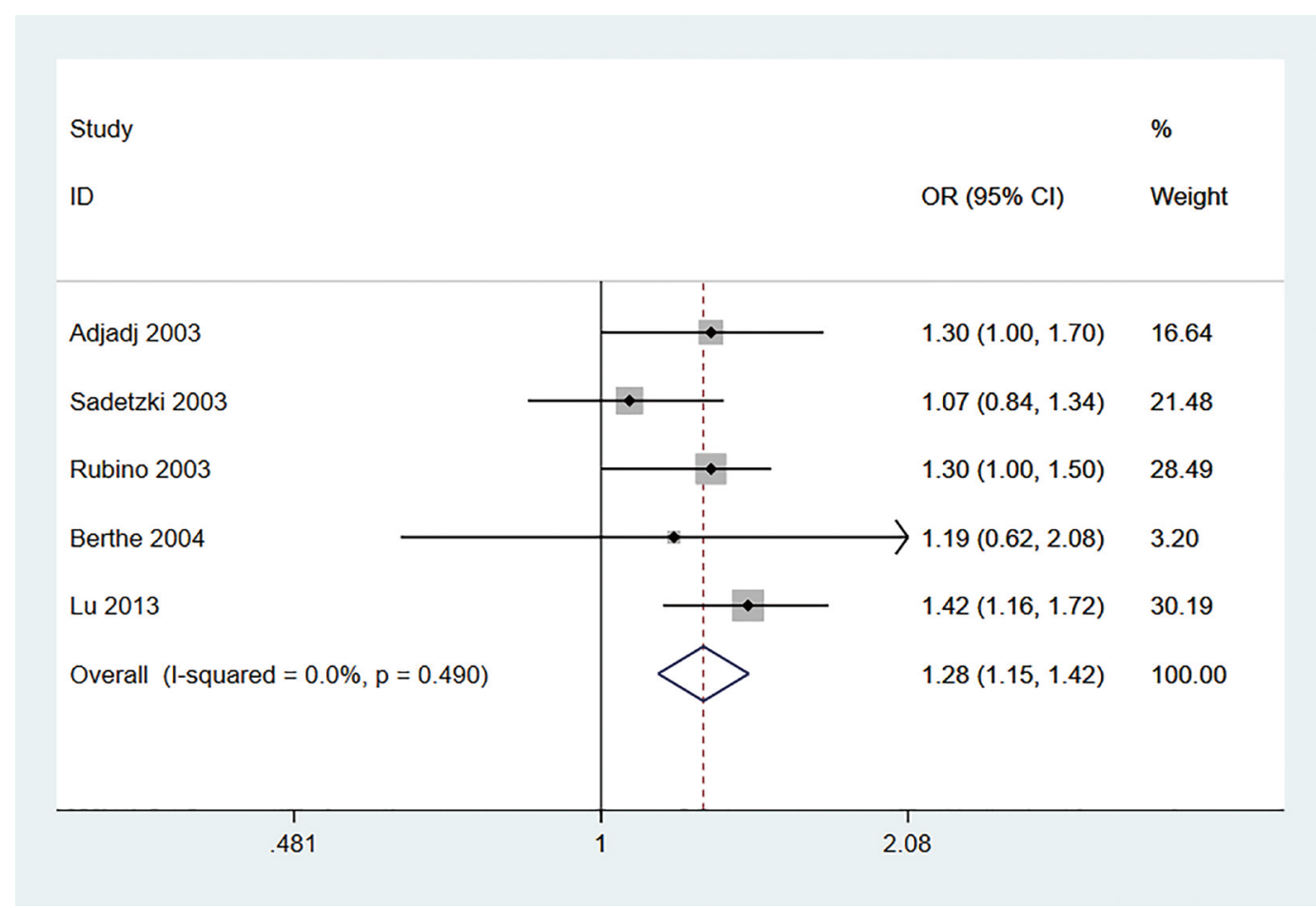

Figure 4 The association between thyroid cancer and the risk of breast cancer. Patients with thyroid cancer are related to an almost 1.3 -times increase in the risks for breast cancer with no heterogeneity being observed $\left[\mathrm{OR}=1.28,95 \%\right.$ CI: $1.15-1.42, \mathrm{P}=0.000 ; \mathrm{I}^{2}=0.0 \%$; enrolling 5 studies (32-36)].

and prevention of $\mathrm{BC}$ in patients with thyroid disease. Additionally, active treatment of hyperthyroidism may reduce the risk of $\mathrm{BC}$.

The results of this meta-analysis demonstrated that in patients with AITD, increased levels of TGAb and TPOAb were associated with an increased risk of BC. This is a summary of the current controversy about whether thyroid auto-antibodies are a risk factor or a protective factor for BC. A causal relationship between AITD and BC has not yet been discovered. Some hypotheses may explain this problem: one possibility is that the immune response to $\mathrm{BC}$ and thyroid can be regulated in the same way. Another possibility is that both thyroid and BC express common antigens such as sodium/iodide symporter (NIS) and TPO antibody (45). Our research results suggest that in the future, it is important for us to dig deeper into the causal relationship between auto-antibodies and the increased risk of BC.

This meta-analysis also demonstrated that patients with thyroid cancer were associated with an increased risk of BC.
Early screening for BC should be performed for patients with thyroid disease to reduce the prevalence of $\mathrm{BC}$ as a secondary malignancy.

There were a few limitations to this meta-analysis. Firstly, several of the included studies adjusted for confounding factors, and as the adjusted variables were not identical in each study, residual confounding factors may still exist. Secondly, since the variables of the study included fewer than 10 articles, the study did not pass the Egger's test for publication bias. Hence, a subjective determination of publication bias was used. The results of the funnel plot analysis suggested more studies are required in future metaanalyses to eliminate publication bias.

\section{Conclusions}

This research demonstrated that hyperthyroidism, AITD, and thyroid cancer are significantly associated with an increased risk of $\mathrm{BC}$, while hypothyroidism can reduce the risk of BC. 
A

Study

$\%$

ID

OR $(95 \% \mathrm{Cl}) \quad$ Weight

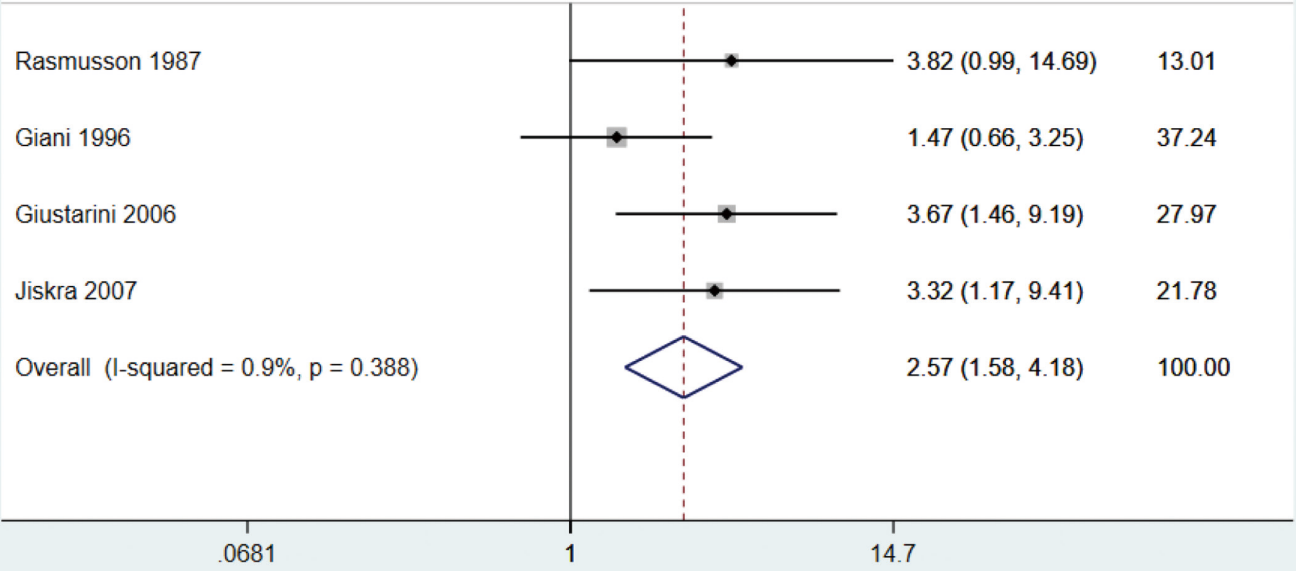

B

Study

ID

\begin{tabular}{|c|c|c|c|}
\hline Giani 1996 & $\rightarrow$ & $3.54(1.50,8.32)$ & 14.95 \\
\hline Smyth 1998 & $\rightarrow$ & $2.26(1.48,3.45)$ & 61.26 \\
\hline Saraiva 2005 & & $\rightarrow 11.51(0.60,221.00)$ & 1.26 \\
\hline Giustarini 2006 & $\rightarrow$ & $5.75(2.11,15.65)$ & 10.93 \\
\hline Jiskra 2007 & $=$ & $3.04(1.15,8.04)$ & 11.60 \\
\hline Overall $(I-$ squared $=3.8 \%, p=0.385$ ) & & $2.83(2.03,3.94)$ & 100.00 \\
\hline
\end{tabular}

Figure 5 The association between the levels of (A) TGAb and (B) TPOAb, and the risk of breast cancer. Elevating TGAb values are related to an almost 2.6-time increase in the risks for breast cancer with low heterogeneity being observed [OR =2.57, 95\% CI: $1.58-4.18, \mathrm{P}=0.000$; $\mathrm{I}^{2}=0.9 \%$; enrolling 4 studies $\left.(14,15,37,38)\right]$, and TPOAb shows greater correlation with breast cancer risk [OR =2.83, 95\% CI: $2.03-3.94$, $\mathrm{P}=0.000 ; \mathrm{I}^{2}=0.0 \%$; enrolling 5 studies (14,15,38-40)] TGAb, thyroglobulin antibody; TPOAb, thyroid microsomal antibody. 


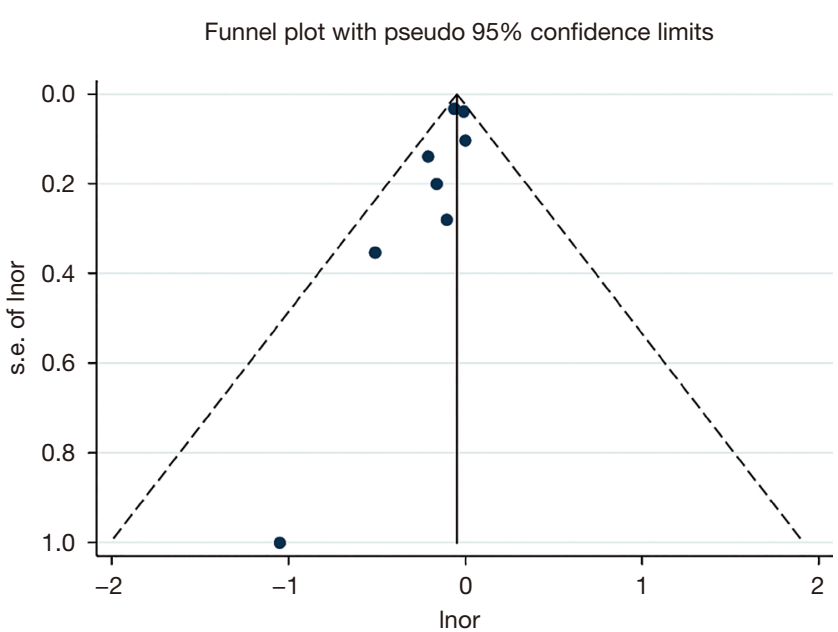

Figure 6 Funnel plot analysis for assessing publication bias.

\section{Acknowledgments}

Funding: This study was funded by the China Soong Ching Ling Foundation (Grant number 2018MZFT-167).

\section{Footnote}

Reporting Checklist: The authors have completed the PRISMA reporting checklist. Available at http://dx.doi. org/10.21037/gs-20-878

Conflicts of Interest: All authors have completed the ICMJE uniform disclosure form (available at http://dx.doi. org/10.21037/gs-20-878). The authors have no conflicts of interest to declare.

Ethical Statement: The authors are accountable for all aspects of the work in ensuring that questions related to the accuracy or integrity of any part of the work are appropriately investigated and resolved.

Open Access Statement: This is an Open Access article distributed in accordance with the Creative Commons Attribution-NonCommercial-NoDerivs 4.0 International License (CC BY-NC-ND 4.0), which permits the noncommercial replication and distribution of the article with the strict proviso that no changes or edits are made and the original work is properly cited (including links to both the formal publication through the relevant DOI and the license). See: https://creativecommons.org/licenses/by-nc-nd/4.0/.

\section{References}

1. Siegel RL, Miller KD, Jemal A. Cancer statistics, 2019. CA Cancer J Clin 2019;69:7-34.

2. Burstein HJ, Temin S, Anderson H, et al. Adjuvant endocrine therapy for women with hormone receptorpositive breast cancer: american society of clinical oncology clinical practice guideline focused update. J Clin Oncol 2014;32:2255-69.

3. Weng $\mathrm{CH}$, Chen $\mathrm{YH}$, Lin $\mathrm{CH}$, et al. Thyroid disorders and breast cancer risk in Asian population: a nationwide population-based case-control study in Taiwan. BMJ Open 2018;8:e20194.

4. Brent GA. Mechanisms of thyroid hormone action. J Clin Invest 2012;122:3035-43.

5. Dong L, Lu J, Zhao B, et al. Review of the possible association between thyroid and breast carcinoma. World J Surg Oncol 2018;16:130.

6. Hardefeldt PJ, Eslick GD, Edirimanne S. Benign thyroid disease is associated with breast cancer: a meta-analysis. Breast Cancer Res Treat 2012,133:1169-77.

7. Angelousi A, Diamanti-Kandarakis E, Zapanti E, et al. Is there an association between thyroid function abnormalities and breast cancer? Arch Endocrinol Metab 2017;61:54-61.

8. Ditsch N, Toth B, Himsl I, et al. Thyroid hormone receptor (TR)alpha and TRbeta expression in breast cancer. Histol Histopathol 2013;28:227-37.

9. Tang HY, Lin HY, Zhang S, et al. Thyroid hormone causes mitogen-activated protein kinase-dependent phosphorylation of the nuclear estrogen receptor. Endocrinology 2004;145:3265-72.

10. Hall LC, Salazar EP, Kane SR, et al. Effects of thyroid hormones on human breast cancer cell proliferation. J Steroid Biochem Mol Biol 2008;109:57-66.

11. Zhang L, Zhang F, Li Y, et al. Triiodothyronine Promotes Cell Proliferation of Breast Cancer via Modulating miR204/Amphiregulin. Pathol Oncol Res 2019;25:653-8.

12. Hercbergs A, Mousa SA, Leinung $M$, et al. Thyroid Hormone in the Clinic and Breast Cancer. Horm Cancer 2018;9:139-43.

13. Gogas J, Kouskos E, Tseleni-Balafouta S, et al. Autoimmune thyroid disease in women with breast carcinoma. Eur J Surg Oncol 2001;27:626-30.

14. Giani C, Fierabracci P, Bonacci R, et al. Relationship between breast cancer and thyroid disease: relevance of autoimmune thyroid disorders in breast malignancy. J Clin 
Endocrinol Metab 1996;81:990-4.

15. Jiskra J, Barkmanova J, Limanova Z, et al. Thyroid autoimmunity occurs more frequently in women with breast cancer compared to women with colorectal cancer and controls but it has no impact on relapse-free and overall survival. Oncol Rep 2007;18:1603-11.

16. Sarlis NJ, Gourgiotis L, Pucino F, et al. Lack of association between Hashimoto thyroiditis and breast cancer: a quantitative research synthesis. Hormones (Athens) 2002;1:35-41.

17. Tosovic A, Becker C, Bondeson AG, et al. Prospectively measured thyroid hormones and thyroid peroxidase antibodies in relation to breast cancer risk. Int J Cancer 2012;131:2126-33.

18. Ronckers CM, McCarron P, Engels EA, et al. New malignancies following cancer of the thyroid and other endocrine glands. In: Curtis RE, Freedman DM, Ron E, et al., editors. New malignancies among cancer survivors: SEER cancer registries, 1973-2000. NIH Publication 05-5302. Bethesda, MD: National Cancer Institute; 2006:375-95.

19. Lee KD, Chen SC, Chan C, et al. Increased risk for second primary malignancies in women with breast cancer diagnosed at young age: a population-based study in Taiwan. Cancer Epidemiol Biomarkers Prev 2008; 17:2647-55.

20. Brown AP, Chen J, Hitchcock YJ, et al. The risk of second primary malignancies up to three decades after the treatment of differentiated thyroid cancer. J Clin Endocrinol Metab 2008;93:504-15.

21. Garner CN, Ganetzky R, Brainard J, et al. Increased Prevalence of breast cancer among patients with thyroid and parathyroid disease. Surgery 2007;142:806-13.

22. Van Fossen VL, Wilhelm SM, Eaton JL, et al. Association of thyroid, breast and renal cell cancer: a population-based study of the prevalence of second malignancies. Ann Surg Oncol 2013;20:1341-7.

23. Cook DA, Reed DA. Appraising the quality of medical education research methods: the Medical Education Research Study Quality Instrument and the NewcastleOttawa Scale-Education. Acad Med 2015;90:1067-76.

24. Brinton LA, Hoffman DA, Hoover R, et al. Relationship of thyroid disease and use of thyroid supplements to breast cancer risk. J Chronic Dis 1984;37:877-93.

25. Moseson M, Koenig KL, Shore RE, et al. The influence of medical conditions associated with hormones on the risk of breast cancer. Int J Epidemiol 1993;22:1000-9.

26. Talamini R, Franceschi S, Favero A, et al. Selected medical conditions and risk of breast cancer. Br J Cancer 1997;75:1699-703.

27. Søgaard M, Farkas DK, Ehrenstein V, et al. Hypothyroidism and hyperthyroidism and breast cancer risk: a nationwide cohort study. Eur J Endocrinol 2016;174:409-14.

28. Chen YK, Lin CL, Chang YJ, et al. Cancer risk in patients with Graves' disease: a nationwide cohort study. Thyroid 2013;23:879-84.

29. Hellevik AI, Asvold BO, Bjoro T, et al. Thyroid function and cancer risk: a prospective population study. Cancer Epidemiol Biomarkers Prev 2009;18:570-4.

30. Chan YX, Knuiman MW, Divitini ML, et al. Lower TSH and higher free thyroxine predict incidence of prostate but not breast, colorectal or lung cancer. Eur J Endocrinol 2017;177:297-308.

31. Sandhu MK, Brezden-Masley C, Lipscombe LL, et al. Autoimmune hypothyroidism and breast cancer in the elderly. Breast Cancer Res Treat 2009;115:635-41.

32. Adjadj E, Rubino C, Shamsaldim A, et al. The risk of multiple primary breast and thyroid carcinomas. Cancer 2003;98:1309-17.

33. Sadetzki S, Calderon-Margalit R, Peretz C, et al. Second primary breast and thyroid cancers (Israel). Cancer Causes Control 2003;14:367-75.

34. Rubino C, de Vathaire F, Dottorini ME, et al. Second primary malignancies in thyroid cancer patients. Br J Cancer 2003;89:1638-44.

35. Berthe E, Henry-Amar M, Michels JJ, et al. Risk of second primary cancer following differentiated thyroid cancer. Eur J Nucl Med Mol Imaging 2004;31:685-91.

36. Lu CH, Lee KD, Chen PT, et al. Second primary malignancies following thyroid cancer: a population-based study in Taiwan. Eur J Endocrinol 2013;169:577-85.

37. Rasmusson B, Feldt-Rasmussen U, Hegedus L, et al. Thyroid function in patients with breast cancer. Eur J Cancer Clin Oncol 1987;23:553-6.

38. Giustarini E, Pinchera A, Fierabracci P, et al. Thyroid autoimmunity in patients with malignant and benign breast diseases before surgery. Eur J Endocrinol 2006;154:645-9.

39. Smyth PP, Shering SG, Kilbane MT, et al. Serum thyroid peroxidase autoantibodies, thyroid volume, and outcome in breast carcinoma. J Clin Endocrinol Metab 1998;83:2711-6.

40. Saraiva PP, Figueiredo NB, Padovani CR, et al. Profile of thyroid hormones in breast cancer patients. Braz J Med Biol Res 2005;38:761-5.

41. Vieira R, Tobar JSS, Dardes R, et al. Alcohol Consumption 
as a Risk Factor for Breast Cancer Development: A Case-Control Study in Brazil. Asian Pac J Cancer Prev 2018;19:703-7.

42. Yang Y, Liu G, Qin L, et al. Overexpression of UHRF1 and its potential role in the development of invasive ductal breast cancer validated by integrative bioinformatics and immunohistochemistry analyses. Transl Cancer Res 2019;8:1086-96.

43. López Fontana CM, Zyla LE, Santiano FE, et al. Hypothyroidism reduces mammary tumor progression via $\mathrm{B}$-catenin-activated intrinsic apoptotic pathway in rats.

Cite this article as: Chen S, Wu F, Hai R, You Q, Xie L, Shu L, Zhou X. Thyroid disease is associated with an increased risk of breast cancer: a systematic review and meta-analysis. Gland Surg 2021;10(1):336-346. doi: 10.21037/gs-20-878
Histochem Cell Biol 2017;147:759-69.

44. Martínez-Iglesias O, García-Silva S, Regadera J, et al. Hypothyroidism enhances tumor invasiveness and metastasis development. PLoS One 2009;4:e6428.

45. Wapnir IL, van de Rijn M, Nowels K, et al. Immunohistochemical profile of the sodium/iodide symporter in thyroid, breast, and other carcinomas using high density tissue microarrays and conventional sections. J Clin Endocrinol Metab 2003;88:1880-8.

(English Language Editors: J. Teoh and J. Gray) 


\section{Supplementary}

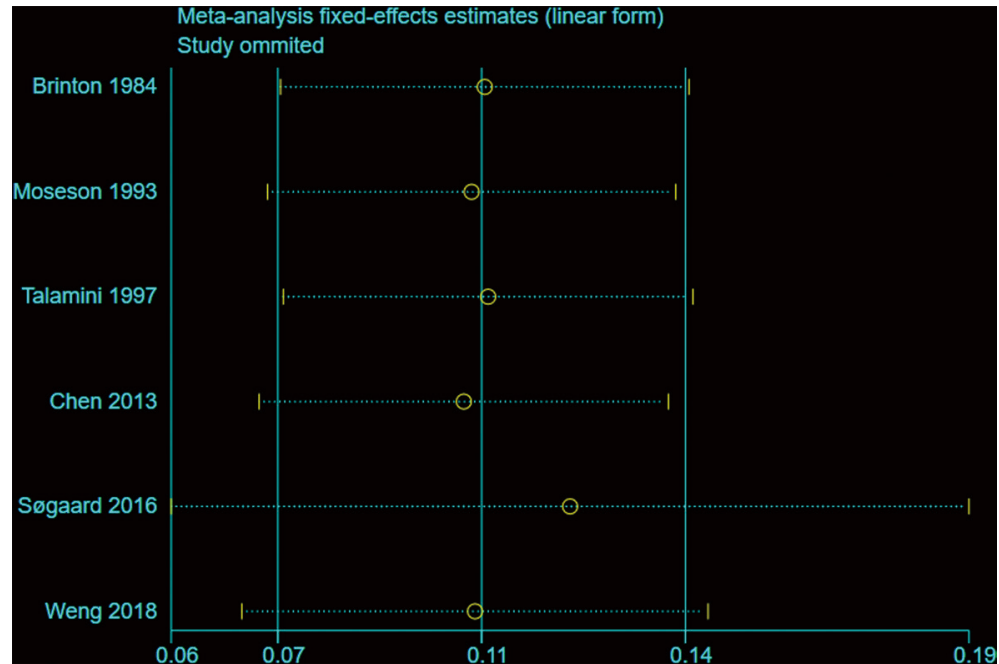

Figure S1 sensitivity analysis of the association between hyperthyroidism and risk of breast cancer.

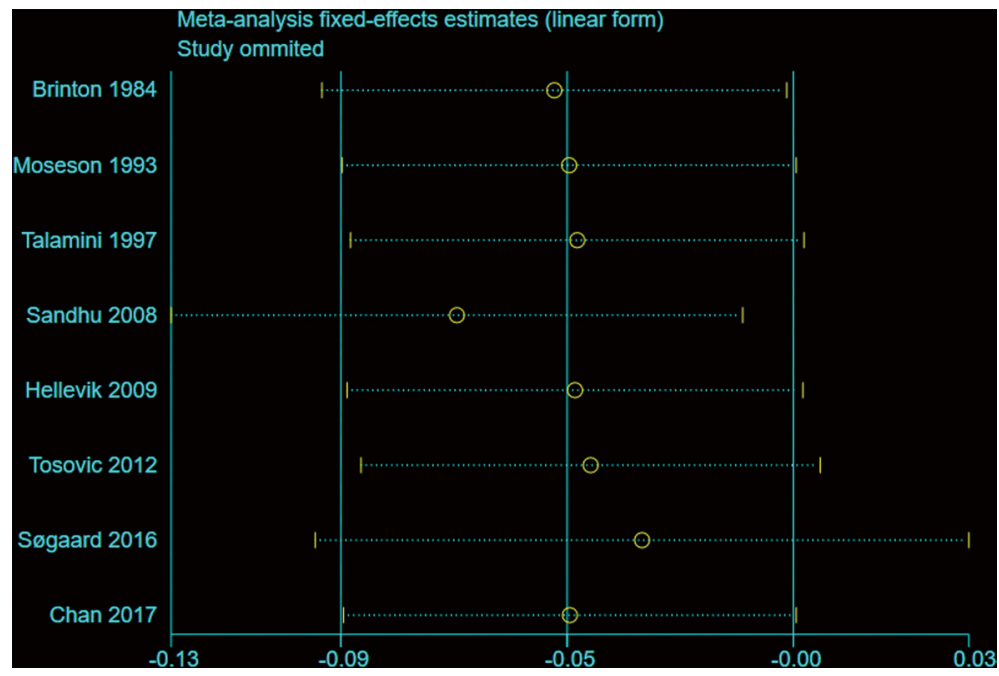

Figure $\mathbf{S} 2$ sensitivity analysis of the association between hypothyroidism and risk of breast cancer. 


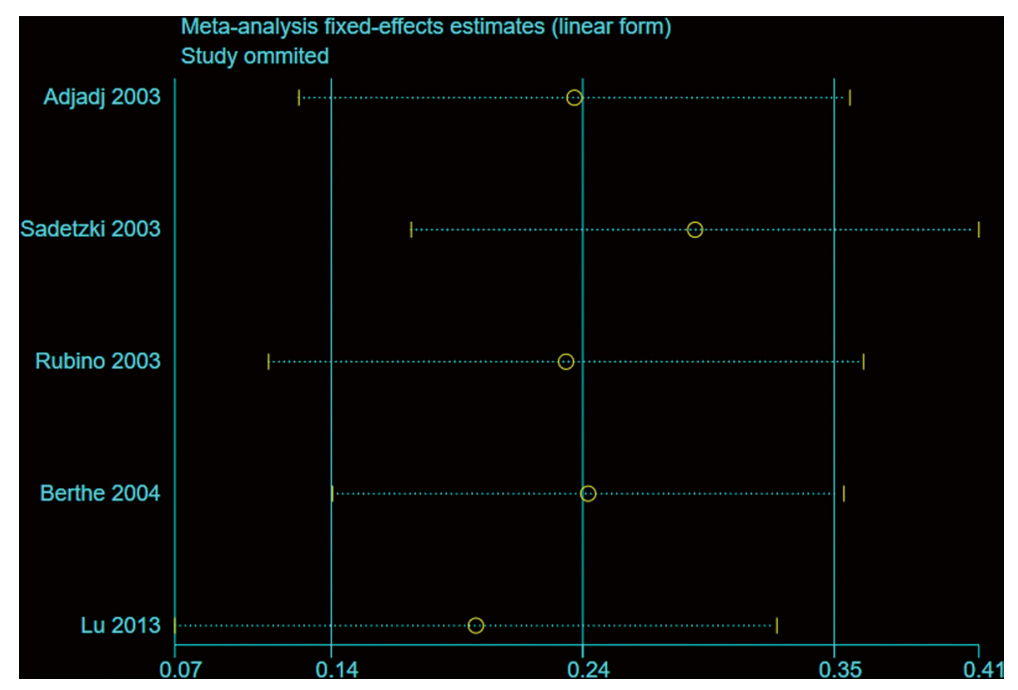

Figure $\mathbf{S} 3$ sensitivity analysis of the association between thyroid cancer and risk of breast cancer.

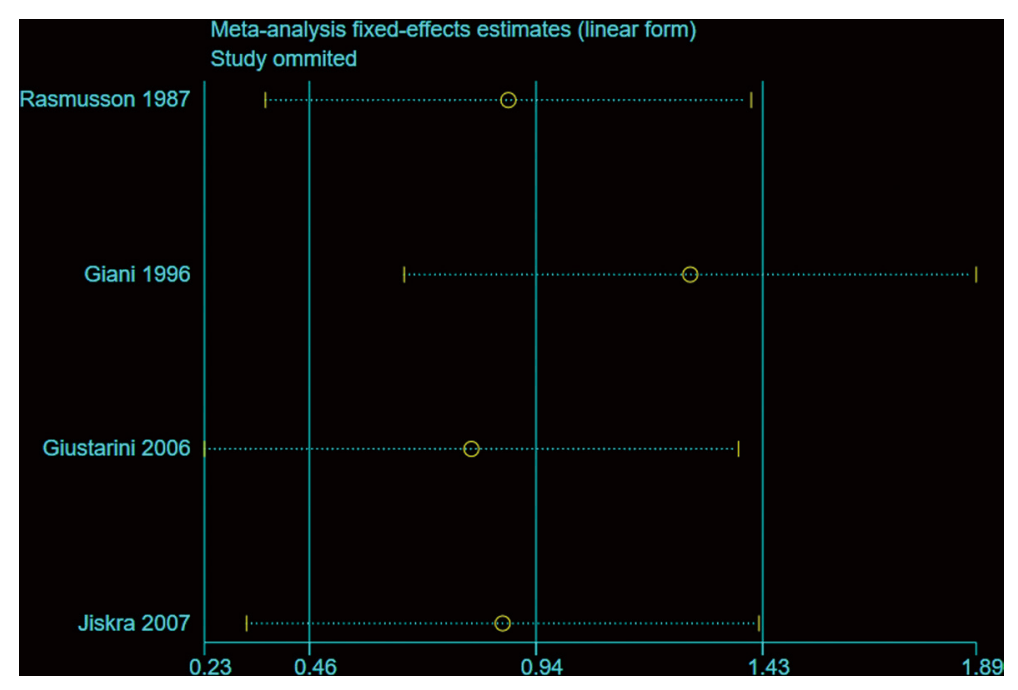

Figure S4 sensitivity analysis of the association between TGAb and risk of breast cancer. 


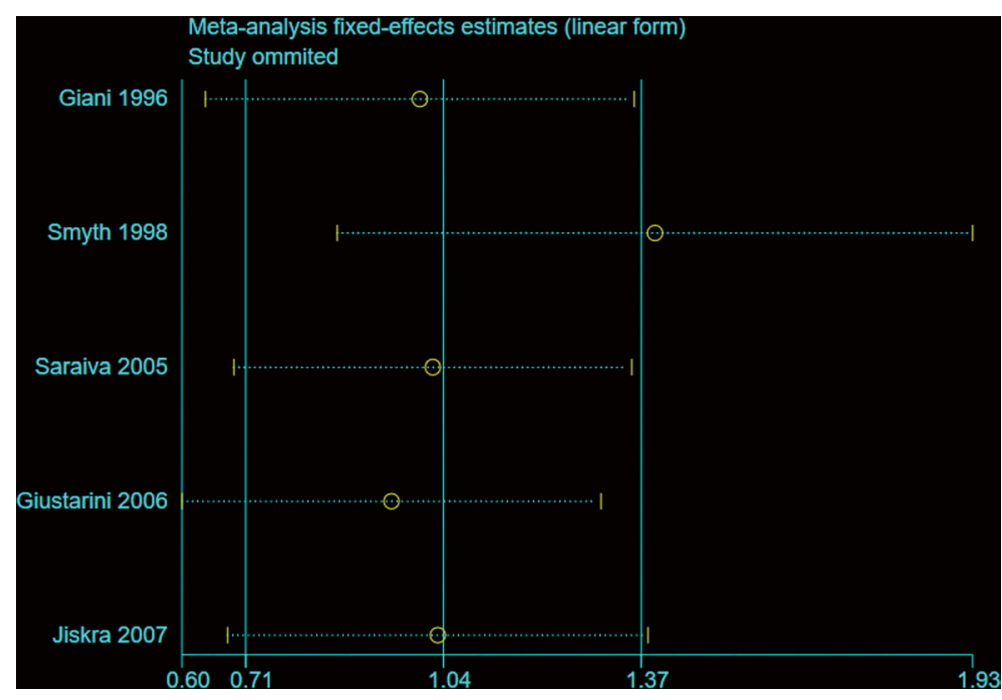

Figure $\mathbf{S} 5$ sensitivity analysis of the association between TPOAb and risk of breast cancer. 